\title{
PanAmazônia sob o viés do Processo Civilizador
}

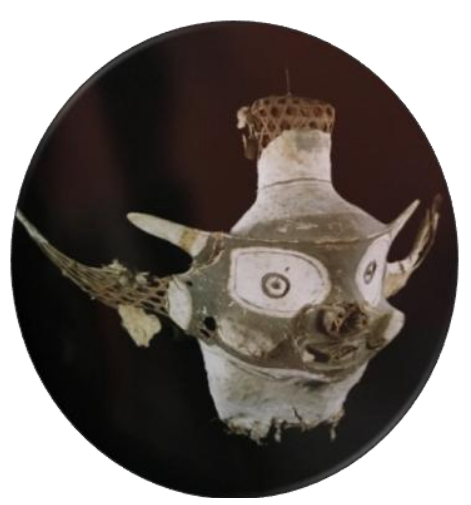

Gláucio Campos Gomes de Matos1

\section{Resumo}

A conferência traz de uma reflexão para atender ao Grupo de Trabalho Processos Civilizadores na PanAmazônia, em decorrência do II Seminário Internacional Sociedade e Cultura na PanAmazônia/2016. Duas questões básicas são levantadas: o que tem a ver a PanAmazônia com o processo civilizador? O que há de em comum entre esses países a permitir uma análise sob o viés do processo civilizador? Sustentado pela pesquisa de campo e análise processual, o artigo destaca: redes de interdependências ampliadas; aponta o europeu - colonizador - em sua autoimagem, considerar os habitantes do novo mundo como seres incivilizados; a presença das missões religiosas entre os grupos étnicos; o processo de integração em curso; a individualização e a diferenciação social ocorrendo; o desenvolvimento das tecnologias e seus efeitos; as discussões ambientais em processo; o surto descivilizadores sobre grupos étnicos, os mecanismos de controle sociais implantados e as novas figurações ocorrendo no universo amazônico.

Palavras-chave: Norbert Elias. Processos Civilizadores. Amazônia. Pan-Amazônia.

\begin{abstract}
The conference brings a reflection to attend the Working Group Civilizational Processes in PanAmazonia, as a result of the II International Seminar Society and Culture in PanAmazonia / 2016. Two basic questions are raised: what does PanAmazonia have to do with the civilizing process? What is there in common between these countries to allow an analysis under the bias of the civilizing process? Supported by field research and procedural analysis, the article highlights: networks of extended interdependencies; points out the European - colonizer - in his self - image, to consider the inhabitants of the new world as uncivilized beings; the presence of religious missions among ethnic groups; the ongoing integration process; individualization and social differentiation occurring; the
\end{abstract}

1 Professor do Programa de Pós-Graduação Sociedade e Cultura na Amazônia (PPGSCA/UFAM) 
development of technologies and their effects; the environmental discussions in process; the outbreak of descivilizadores on ethnic groups, the mechanisms of social control implanted and the new figurations occurring in the Amazonian universe.

Keywords: Norbert Elias. Civilizing Processes. Amazon. Pan-Amazon.

Para Norbert Elias (2006, p.37) O processo civilizador corresponde a um percurso de aprendizagem involuntária pelo qual passa a humanidade. Começou nos primórdios do gênero humano e continua em marchar com inúmeras vicissitudes, no presente momento. Não há fim à vista, só a direção é clara.

Seguindo o estilo de Norbert Elias, dou continuidade a esse escrito indagando: $O$ que tem a ver a Pan-Amazônia com o processo civilizador?

A Pan-Amazônia ${ }^{2}$ se configura geopoliticamente em 1978, momento em que oito países da America do Sul e denominados amazônicos - Brasil, Bolívia, Colômbia, Equador, Guyana, Peru, Suriname e Venezuela - assinaram o Tratado de Cooperação Amazônica (TCA) e posteriormente a Organização do Tratado de Cooperação Amazônica (OTCA), com o objetivo de promover o desenvolvimento harmônico da região e o bem-estar de suas populações, além de reforçar a soberania dos países sobre seus territórios amazônicos. Pois o conhecimento nos proporcionou entender que a Amazônia é a maior floresta tropical do mundo. Há 34 milhões de habitantes e onde vivem 420 povos indígenas, que falam 86 idiomas e 650 dialetos e alguns vivendo isolados. A região se destaca pelo volume de recursos naturais os quais podem contribuir com o desenvolvimento económico e social dos seus povos.

2 Ministério das Relações Exteriores/Brasil http://www.itamaraty.gov.br/pt$\mathrm{BR} /$ politica-externa/integracao-regional/691-organizacao-do-tratado-decooperacao-amazonica-otca; Organização do Tratado de Cooperação Amazônica (OTCA) - Em dezembro de 2002, foi assinado, no Palácio do Planalto, o Acordo de Sede entre o Governo brasileiro e a OTCA, que estabeleceu a sede da Secretaria Permanente da Organização em Brasília http://otca.pagina-oficial.com/amazon/our_amazon 
A configuração do que hoje se denomina Pan-Amazônia é resultado de uma longa aprendizagem no andamento desse processo. A criação do tratado nos coloca frente a um processo de integração em curso. Numa análise, vemos o desenvolver de uma figuração complexa, na qual convergem metas e objetivos comuns para defender e conservar esse ambiente peculiar que está resguardado a um espaço geográfico, ocupado por muitos humanos e não humanos, o qual se mostra essencial para o equilíbrio ambiental do planeta. A racionalidade do uso de seus recursos naturais e a preocupação com a habitabilidade para o seu povo é um desafio, porém não podemos deixar os ideais românticos nos ofuscarem, pois: "Há de se entender que o processo planejado, racional de ocupação da Amazônia e, dentre seus Estados, o Amazonas, não deixa de ser um processo cego, fruto de metas e objetivos de seres humanos individuais ou de grupos”. (MATOS, 2015, p. 235)

No decurso de longo prazo do processo civilizador, houve conseqüências percebidas quando de uma análise pretérita: "No processo civilizatório, o homem se individualizou e se tornou menos sensível ao ambiente". Atomizado, sentiu-se superior e se afastou da essência de suas origens naturais. Vivendo como um ser eminentemente sociocultural virou as costas para o ambiente. Essa marca do retrocesso o fez negar sua natureza e procurou domar a natureza usufruindo dela ao extremo. Perdeuse ou quase se perde em seu empoderamento econômico, científico e tecnológico. Mas vez ou outra percebe que não tem autonomia de sua existência. Para manter-se vivo, precisa dentre outros elementos naturais: o ar para respirar, o mesmo ar que ele polui. Para hidratar o corpo, precisa de água, a mesma água que polui. Precisa de elementos naturais que por natureza da espécie humana não tem autonomia de autossuficiência. (MATOS, 2015, pp. 116/ 7).

A Organização do Tratado de Cooperação Amazônica é um exemplo do planejamento humano a partir de análise pretérita a qual nos 
permitem visualizar relações de interdependências funcionais, assim como, limita a autonomia de seus integrantes, mas, ao mesmo tempo, possibilita poder. O Estado se mostra presente e direciona regras de condutas, mecanismos de controle e um novo nível, embora ainda em fase de amadurecimento, de sensibilidade frente ao ambiente se faz notar no curso do mesmo processo civilizador. Entretanto, há de convirmos que todo processo de integração desencadeia um processo de desintegração interno, cabendo ao pesquisador, ao definir seu objeto de estudo, poder revelar. Ou seja, tensões e conflitos surgem e devem ser resolvidos à base do diálogo ou da diplomacia.

Porém não me aproprio apenas de fatos recentes para responder às indagações iniciais, e pergunto: o que há de em comum entre esses países a permitir uma análise sob o viés do processo civilizador?

Penso ter respondido a questão, em parte, nas reflexões acima. Em outra, no que se refere à América do Sul, há de em comum, graças às pesquisas arqueológicas ${ }^{3}$ o fato de se encontrar vestígios da presença humana nessa vasta região a mais de 11 mil anos, portanto, na perspectiva socioecológica (Goudsblom, 2001) e não menos de Elias (1994) há de se compreender a existência de níveis de civilização na região, assim como, mudanças de comportamento e níveis de poder existentes nessas sociedades.

3 Consultar pesquisas da arqueóloga Niède Guidon realizadas na Serra da Capivara na região de São Raimundo Nonato no estado do Piauí - Brasil.

Em Figueiredo (2011, p.14), a periodização com relação à Amazônia, embora provisória vá em oposição à terminologia usada para o Velho Continente. Para este se utiliza a Idade da Pedra Lascada e Idade da Pedra Polida ou Idade dos Metais. No caso da Amazônia usa-se as fases Paleoindígena - 11.00 a 7.500 a.C, Arcaica -7.500 a 1.000 a.C e Pré-história Tardia - 1.000 a.C a 1.000 d.C. O autor aponta de que na Amazônia há evidências da presença do homem americano a partir de 14.700 a. C. Portanto, os dados proporcionam elementos essenciais para o entendimento do processo civilizatório nessa região. A começar pelos pares de oposto Velho Mundo e Novo Mundo, que segundo Silva (2004, p. 21) “o Velho e o Novo Mundo encontram-se em 1492 (descoberta do Continente Americano)". 
Um corte na história nos proporciona informações de fatos em comuns ocorridos na região designada hoje de PanAmazônia. Dentre essas há evidências de massacre de grupos indígenas que na região viviam; a presença de religiosos entre grupos étnicos e o modelo de comportamento ocidental impostos por eles e, não menos, a exploração de recursos naturais nesses países.

E, olhando daqui, o que tem a ver isso com todos nós? Isso te a ver com o que somos hoje e as metas e objetivos pensados para o amanhã, a exemplo a criação da Organização do Tratado de Cooperação Amazônica. Em outras palavras, sem dá atenção ao longo processo de desenvolvimento da sociedade compreendemos pouco sobre nós mesmos e o longo caminho de aprendizagem, por vezes doloroso, por qual passamos.

Diante desses fatos históricos há de ser considerado outro elemento em comum, o de termos sidos colonizados pelo europeu que "descobriu" esse espaço geográfico existente. Veio em busca de riquezas e encontrou um ambiente propício para explorar. Porém, encontrou seres humanos e teve que domar sua natureza.

O colonizador, em sua autoimagem, a partir de comportamentos e condutas já edificadas em seu país de origem, desconsiderou o nível e preceitos civilizacionais dos habitantes do Novo Mundo e os considerou como seres selvagens e incivilizados. Portanto, há de entender, que a referência em si ou no nós sociedade do Velho Mundo, isto é, a autoimagem do colonizador, foi um diferencial ao observar os estabelecidos do espaço que hoje se denomina PanAmazônia. Ele se percebe como um ser civilizado, superior, ao se deparar com os estabelecidos. Nas palavras de Elias (1994, p. 64), "na verdade, uma fase fundamental do processo civilizador foi concluída no exato momento em que a consciência de civilização, a consciência da superioridade de seu próprio comportamento e sua corporificação na ciência, tecnologia ou arte começaram a se espraiar por todas as nações do Ocidente". 
Para Elias (2006, p.37) O processo de civilização está relacionado à autorregulação adquirida, imperativa para a sobrevivência do ser humano. Sem ela, as pessoas ficariam irremediavelmente sujeitas aos altos e baixos das próprias pulsões [urges], paixões e emoções, que exigiriam satisfação imediata e causariam dor caso não fossem saciadas. De forma mais objetiva, o processo civilizador, (ELIAS, 1993, p. 193-4), “... constitui uma mudança na conduta e sentimentos humanos rumo a uma direção muito específica,... que pessoas isoladas no passado não planejaram essa mudança, essa "civilização", deliberada.” Porém seguiu uma ordem no sentido “... do controle efetuado através de terceiras pessoas é convertido, de vários aspectos, em autocontrole, que as atividades humanas mais animalescas são progressivamente excluídas do palco da vida comunal e investidas de sentimentos de vergonha, que a regulação de toda a vida instintiva e afetiva por um firme autocontrole se torna cada vez mais estável, uniforme e generalizada." Nesse caso, há uma força oculta, independente de qualquer indivíduo, que marcha para frente, nesse processo.

Portanto, os países da Pan-Amazônia - Brasil, Peru, Colômbia, Bolívia, Equador, Venezuela, Guianas e Suriname - não escaparam desse processo aos moldes, não dos orientais e muito menos dos indígenas da região, mas dos europeus. Expressões a exemplo "essa é uma educação eurocêntrica", "essa é uma visão eurocêntrica" são comumente colocadas em debates fúteis e por vezes inconclusivos, chegando ao mesmo ponto de partida. Assim, querendo ou não admitir, nós da América do Sul, constituintes da PanAmazônia, quer sejamos não índios ou indígenas, não escapamos do modelo de processo civilizador ocidental e até onde se vê, talvez este seja o martírio vivido por alguns egos, não tivemos e ainda não encontramos meios de nos livramos dele. Se é que queremos.

As indagações iniciais vão sendo respondidas à medida que a teoria se coaduna com o empírico. Para Elias (1993) o conceito de civilização “... resume tudo em que a sociedade ocidental dos últimos dois 
ou três séculos se julga superior a sociedades mais antigas ou a sociedades contemporâneas "mais primitivas". E sem delongas, vamos ver: "Com essa palavra, a sociedade ocidental procura descrever o que lhe constitui o caráter especial e aquilo de que se orgulha: o nível de sua tecnologia, a natureza de suas maneiras, o desenvolvimento de sua cultura científica ou a visão do mundo, e muito mais." Incorporamos tal concepção. Faz parte de nossa personalidade.

No que vimos, não há na história sociedades incivilizadas, mas níveis de civilização diferenciados, atribuindo-lhes, dependendo do tempo e espaço de quem as analisa, a estigmatização de incivilizadas. Dessa forma, e esse foi um dos efeitos negativos, se assim podemos compreender, da chegada dos colonizadores ao observar, em sua autoimagem, a civilização dos povos colonizados. Destarte, do que foi escrito, chamo atenção para objetos de estudos, problemas de pesquisa que estão à nossa frente e podem ser revelados sob o viés da teoria eliasiana. Da mesma forma, se olharmos apenas efeitos negativos no contexto do mesmo processo, deixa de ser uma análise na perspectiva sociológica.

No cotidiano observamos e por vezes nos surpreendemos com mudanças ocorrendo no contexto da sociedade. O olhar imediatista ofusca o longo processo por quais passam essas mudanças até que sejam identificadas no cotidiano. Boas maneiras, hospitalidade, regras de etiquetas, indivíduo educado, limiar de vergonha e de nojo, repugnância à violência, gentileza, sensibilidade ao outro diferente, controle das emoções, autocontrole, diferenciação social entre outras palavras significadas pela semântica permeiam os habitantes da PanAmazônia no curso do processo civilizador ocidental. Concomitantemente, à medida que nos tornamos mais autocontrolados e o aperfeiçoamento de outras qualidades ao bem viver social, desenvolvemos uma qualidade especificamente humana, que é capacidade de dissimulação. Nós a aperfeiçoamos e colocamos em prática nas especificidades das figurações que nos inserimos. O observador se 
surpreende que o indivíduo que conhece é o mesmo que causou um ato ilícito.

No que se refere à individualização, nas sociedades complexas dos nossos dias, não deixa de ser percebida e de incomodar. Ela constitui parte desse processo nas relações entre seres humanos. Nossa individualização se mostra mais retraída em algumas figurações e mais cooperativa em outras.

No dia a dia ouvimos expressões a exemplo: somos família, vocês são irmãos. Essa visão biológica passa a surpreender a sociedade quando há conflitos em família a ponto de mortes entre irmãos, pais e filhos.

É no cotidiano, para suavizar a carga biológica, mas não lhe dando o direito a herança de família quando na repartição de bens, ouvimos expressões: somos irmãos ou filhos de coração, ou somos irmãos de fé. No primeiro o coração assume um ente autônomo no ser individualizado e fechado em suas relações. Para abrandar nosso desespero, e acreditando na salvação, invocamos a onipresença do Espírito Santo. No cotidiano, o biológico é o responsável em gerar os seres humanos, mas não é ele a mantê-los unidos. São as relações afetivas que sustentam os homens e mulheres e isso é um diferencial social. Nas discussões que se mostram com relação às diferenças, é o afetivo que mantém, sem jugo, as relações de convivência entre negros, brancos, pardos, amarelos, índios, homossexuais, deficientes, ou ainda, o pobre e o rico. Porém, é esse ser constituído biologicamente, diferente de qualquer outra espécie, a controlar sua natureza. Uma espécie que só é possível compreender sua natureza humana levando em consideração o seu alicerce biológico.

No que se refere à Pan-Amazônia, centro o foco no território brasileiro, especificamente na região norte, onde destaco o Amazonas e caminho pela reflexão teórica, entre outros autores, através da teoria de Norbert Elias e os pressupostos de Johan Goudsblom. Sob o viés da sociologia figuracional/processual observo processos de longo prazo ocorrendo no Amazonas. Parto do trabalho de campo em três 
comunidades rurais e posteriormente dilato o olhar para o Amazonas, sem, entretanto, ter a pretensiosidade universal. Porém, instigo o leitor, a partir das indagações iniciais, a deslocar o seu olhar reflexivo aos países da PanAmazônia e elencar, à medida das proximidades, as convergências dos achados.

No processo de integração, compreendo o par de opostos - rural e urbano - em transição, pois o rural nem sempre tarda a ser urbano. E quanto mais o urbano avançar, no sentido de metrópole, as mudanças vão ocorrendo.

Em comunidades designadas geopoliticamente de rural, o amazônida desenvolve suas atividades no ambiente terrestre e aquático. Seu modo de vida está vinculado às oscilações das vazantes e enchentes do rio. Adaptado ao clima quente e úmido realiza atividades de baixo a moderada intensidade. Um ritmo aprendido desde cedinho, não no interior da escola, mas na convivência com os membros da família e no dia a dia da comunidade. Tal conhecimento lhe permite mediar o esforço sem que leve o corpo a exaustão precoce. A adaptação de desenvolvimento e ajustes culturais tem permitido sua permanência nesse ecossistema. $O$ conhecimento local, hoje denominado etnoconhecimento, permitiu ao amazônida compreender os ciclos naturais, o comportamento dos animais, a piracema, floração e frutificação de determinadas espécies, hábitos noturno, diurno e alimentar dos animais silvestres adequando-os ao tempo macro (calendário) e micro (do relógio). O distanciamento tornou o homem destemido. Perdeu seus medos dos seres dos rios e da floresta. Explorou-os em detalhes e se beneficiou do ambiente.

Sustento que o Amazonas, em pleno Séc. XXI, ainda vive o regime do fogo. Nas comunidades o fogo é utilizado para o domínio e controle da natureza, preparo e fertilização do solo. Mas quem longe está da figuração do regime do fogo, pouco entenderá sobre ela. Entretanto, por quanto tempo durar, o regime do fogo não deve continuar. Se a 
orientação científica está na direção certa, a floresta amazônica em pé terá maior importância no equilíbrio ambiental do que em forma de carvão.

A existência de comunidades amazônicas é aferida pela oralidade, entretanto as evidências dos sítios arqueológicos - a conhecida Terra Preta de Índio ou Terra Genealógica - permitem afirmar que tais áreas já sentiram a presença de humanos (grupos étnicos/indígenas) a mais de 7.000 anos. Se o fogo não teve outra forma de ser ateado, a terra Genealógica traz evidência de sua utilização por humanos. Dessa forma, onde há uso do fogo controlado, há organização social e nesse caso há civilização. Portanto, qualquer escrito na história referindo-se a indígenas como seres incivilizados é um lapso na análise.

É por uma reflexão na perspectiva socioecológica que sustento haver evidências de que a relação dos primeiros homens com a natureza era de interação. Ao integrarem-se à natureza há evidencias da existência de regras de condutas para com o ambiente. Em outras palavras, as condutas, as normas com relação com o ambiente - natureza - era de respeito funcional, diferentemente dos não índios, que aqui chegaram e se designavam, em suas autoimagens, de civilizados.

Os colonizadores fizeram do Amazonas por extensão a Amazônica, uma prateleira de matéria prima a atender figurações do Velho Mundo. A figuração a decorrer por todo o período da colonização se manifesta pelo uso da força, estratégias e tecnologia para dominar a natureza, incluindo a natureza indígena.

Com relação à água, elemento natural em abundância na Amazônia, eu instigo o leitor a refletir, no curso do processo civilizador, que o cuidado com o uso e controle da água ainda não ficou inerente ao dever social. Os instrumentos coercitivos ainda são incipientes na vida de muita gente. Tema em discussão global, o uso da água está nos exigindo maior grau de organização social. 
Sustento, com referências aos registros históricos e na oralidade de procedentes de grupos étnicos, o fato de o Amazonas ter, com consentimento social, vivido um surto descivilizatório no espoliar, escravizar, matar e se apropriar dos indígenas.

Ao direcionar a reflexão para os indígenas, suscito que o processo de integração desencadeou um processo de desintegração interna. A tradição cultural guerreira de embate físico é suavizada pelo diálogo. O Estado ao mesmo tempo em que monopoliza a força física obriga os indivíduos à convivência pacífica. Isso impõe a esse indivíduo a economia psíquica, o autocontrole.

Vemos indígenas se postando para a guerra - o habitus guerreiro mas é no diálogo que se resolve as tensões/ problemas, e não no desfecho de flechas contra os não índios. Nesse processo grupos étnicos deixaram de falar sua língua materna; ocorreu a informalização dos seus costumes (sentar para ouvir as experiências dos mais velhos); a formação/educação que era de responsabilidade da identidade nós aldeia, começa a centrar na escola formal. Hoje a memória não é a única referência do conhecimento passado pela oralidade, pois a escrita já foi absorvida; os indivíduos que aprendiam no cotidiano, agora seguem regras do tempo cronometrado; o pajé perdeu sua função para a medicina dos não índios; o seu Deus agora é Jeová.

Destaco que no processo de integração o nós cedeu para o eu. Agora vemos com mais evidência a individualização. $\mathrm{O}$ en, culturalmente amparado pelo nós aldeia, está "só” para tomar suas decisões. Nos suicídios ocorrendo em grupos étnicos, não há nenhum ser sobrenatural habitando a mente do indivíduo. Há de se averiguar se o processo de integração desequilibrou a balança nós/eu. Há de se dar atenção ao fato do eu, agora individualizado, não está com dificuldade de resolver questões de identidade. Mas é também, nesse mesmo processo que observamos o empoderamento dos grupos étnicos. Se em uma determinada época grupos 
étnicos eram rivais, hoje em nome da identidade nós indígena, se unem e fortalecem o poder.

No avançar do processo de integração maior foi a incorporação de energia no universo amazônico. O homem deixou a tecnologia do machado de pedra para o de aço, posteriormente ao da motosserra, aos herbicidas e a natureza sentiu seus efeitos; da zarabatana avança para a espingarda e com um único disparo tem 20 ou mais possibilidade de acerto contra uma única chance do dardo; as redes/malhadeiras confeccionadas com linhas de resistências variadas e malhas para todas espécies abalaram a diversidade ictiológica da região; do remo passou para o motor de rabeta, posteriormente às máquinas de autopropulsão. As máquinas de força de 4, 15, 30hp, foram superadas por máquinas de força de 550, 700, 915hp. As embarcações cuja capacidade de levar 30, 60 pessoas passou a transportar 200, 300, 400 pessoas para as sedes dos municípios. Isso fez o Amazonas sentir o efeito do crescimento extensivo e intensivo; a integração leva: o telefone celular e a luz elétrica. A região começa a sentir o efeito dos resíduos sólidos dos eletros domésticos e eletroeletrônicos. As atividades miméticas na TV provocam momentos de excitação ao espectador.

O ethos é o modo de vida do amazônida expresso no extrativismo animal, vegetal, cultivo do solo e na criação de animais. Tanto nas diversas técnicas de pescar quanto na caçada destaco o conhecimento das relações ecológicas o qual permitiu grandes vantagens dos humanos sobre os não humanos; no cultivo do solo enfatizo o plantio da roça e a força da ajuda mútua na atividade do puxirum, mutirão ou ajuri, componente do habitus amazônico; a criação de boi levou ao maior desflorestamento em áreas de terra firme e de várzea e o ambiente de caçada e de pesca ficou mais distante da casa do amazônida.

O criador de boi por estar ligado a essa figuração não tem autonomia de ditar as regras em sua fazenda, pois, o mesmo encontra-se ligado a uma grande rede internacional de criadores e consumidores e as 
discussões ambientais que tencionam com o sistema de criação extensivo praticado na região amazônica. Descrevo também o abate do boi na região e destaco o abate humanitário no curso do processo civilizador.

Entretanto, com as figurações ampliadas e as redes invisíveis de consumidores, as atividades de pesca, de caça de animais silvestres, a retirada de madeira, passaram a ser entendidas como predatórias. Isso é observado em vários municípios do Amazonas. Os pronomes pessoais como modelos figuracionais nos colocam no contexto dessas figurações. Isso quer dizer que ninguém, até agora, foi autuado ou preso por distúrbio de comportamento por estar envolvido com essas questões, hoje tidas como ilegais. Esses indivíduos são autuados por estarem ligados a redes invisíveis que fazem pressionar o ambiente. Cabe-nos, ou a quem interessar revelar as pretensões, metas, objetivos que movem essas figurações.

A sociologia do lazer de Elias e Dunning permite entender a busca de emoções prazerosas na prática do futebol e outras atividades miméticas ocorrendo na hinterlândia amazônica. Sustento que, em tempos de crise, a força do marketing para atrair turistas aos municípios do Amazonas não está no trabalho mais na esfera do lazer. Isso se constata nas festas em todos os seus sessenta e dois municípios, acompanhado do esplendor de seu paisagismo. Se a Amazônia foi inventada pelos viajantes do Velho Mundo, é, estrategicamente, sob o viés da sociologia do lazer, um espaço exótico de visitação e da apropriação da relação entre trabalho e lazer.

Por intermédio do lazer, sustento a idéia de ser trabalhado um olhar mais sensível para o ambiente. Nessa esfera deve-se dar voz ao amazônida, ao estabelecido conhecedor das matas e dos rios. Ele deve apresentar aos outsiders o ambiente que vive, não como servo, mais como conhecedor. Apresentar a árvore (seringueira) que sangrou na época da borracha e fez surgir em meio à floresta a París dos Trópicos, mas que muitos indivíduos sangram para isso. $\mathrm{O}$ mateiro pode apresentar o pau-rosa 
(Aniba rosaeodora), a árvore que Marilyn Monroe, com o Chanel $\mathrm{n}^{0} 5$, quase leva à extinção para perfumar corpos pelo mundo ocidental.

No processo de integração a diferenciação social avança no Amazonas e o maior grau de interdependência funcional se faz revelar. Em todos sessenta e dois municípios do Amazonas, vemos a presença do ensino superior e o filho do pescador, do agricultor, o indígena no mínimo será professor. Isso provoca tensões em determinadas práticas que ocorrem nesses municípios e as relações de poder começam a mudar.

A força oculta do processo civilizador avança sobre as comunidades amazônicas, sejam de não índios como indígenas. A direção observada é no sentido do autocontrole, do controle das emoções, da economia psíquica. As regras de boas maneiras, as palavras mágicas (bom dia, boa tarde, boa noite, licença, desculpa, obrigado) desde cedinho habitam as escolas dos não índios como as indígenas. Espera-se que a escola molde o comportamento do indivíduo. Espera-se que a escola torne o indivíduo educado. Que o sentimento de vergonha se instale que a repugnância frente à violência se evidencie. Mas é, não no domínio da natureza, e sim nas relações sociais que se observam as maiores tensões e conflitos no universo amazônico.

Por fim, se o Amazonas/Amazônia é o que é hoje, é em consequência de planejamento dos humanos.

\section{Referências}

ELIAS, N., O processo civilizador. Rio de Janeiro: Jorge Zahar Editora, 1993 .O processo civilizador. Rio de Janeiro: Jorge Zahar Editora, 1994b . Introdução à sociologia. Lisboa: Edições 70, 1980

- Conceito de Civilização. In.: Escritos \& ensaios; 1: Estado, processo, opinião pública. Organização e apresentação, Federico Neiburg e Leopoldo Waizbort. Rio de Janeiro: Jorge Zahar Ed., 2006 
GOUDSBLOM, J., Pensar com Elias. In.: Norbert Elias: a politica e a história. Alain Garrigou e Bernard Lacroix (orgs.). São Paulo: Editora Perspectiva, 2001.

MATOS, G. C. G. de, Ethos e figurações na binterlândia amazônica. Manaus: Editora Valer/Fapeam, 2015 